\title{
Administration of single-dose GnRH agonist in the luteal phase in ICSI cycles: a meta-analysis
}

\author{
João Batista A Oliveira ${ }^{1,2,3^{*}}$, Ricardo Baruffi ${ }^{2,3}$, Cláudia G Petersen ${ }^{1,2,3}$, Ana L Mauri ${ }^{2,3}$, Mario Cavagna ${ }^{2}$, \\ José G Franco $\mathrm{Jr}^{1,2,3}$
}

\begin{abstract}
Background: The effects of gonadotrophin-releasing hormone agonist ( $\mathrm{GnRH}-\mathrm{a}$ ) administered in the luteal phase remains controversial. This meta-analysis aimed to evaluate the effect of the administration of a single-dose of GnRH-a in the luteal phase on ICSI clinical outcomes.
\end{abstract}

Methods: The research strategy included the online search of databases. Only randomized studies were included. The outcomes analyzed were implantation rate, clinical pregnancy rate (CPR) per transfer and ongoing pregnancy rate. The fixed effects model was used for odds ratio. In all trials, a single dose of $\mathrm{GnRH}$-a was administered at day $5 / 6$ after ICSI procedures.

Results: All cycles presented statistically significantly higher rates of implantation ( $P<0.0001)$, CPR per transfer ( $P=$ 0.006) and ongoing pregnancy $(P=0.02)$ in the group that received luteal-phase $G n R H-a$ administration than in the control group (without luteal-phase-GnRH-a administration). When meta-analysis was carried out only in trials that had used long GnRH-a ovarian stimulation protocol, $C P R$ per transfer $(P=0.06)$ and ongoing pregnancy $(P=$ 0.23 ) rates were not significantly different between the groups, but implantation rate was significant higher $(P=$ 0.02 in the group that received luteal-phase-GnRH-a administration. On the other hand, the results from trials that had used $\mathrm{GnRH}$ antagonist multi-dose ovarian stimulation protocol showed statistically significantly higher implantation ( $P=0.0002)$, $C P R$ per transfer $(P=0.04)$ and ongoing pregnancy rate $(P=0.04)$ in the luteal-phase$\mathrm{GnRH}-\mathrm{a}$ administration group. The majority of the results presented heterogeneity.

Conclusions: These findings demonstrate that the luteal-phase single-dose $\mathrm{GnRH}-\mathrm{a}$ administration can increase implantation rate in all cycles and CPR per transfer and ongoing pregnancy rate in cycles with GnRH antagonist ovarian stimulation protocol. Nevertheless, by considering the heterogeneity between the trials, it seems premature to recommend the use of $\mathrm{GnRH}-\mathrm{a}$ in the luteal phase. Additional randomized controlled trials are necessary before evidence-based recommendations can be provided.

\section{Background}

The depletion of granular cells due to follicular aspiration and the suppression of the release of luteinizing hormone (LH) by analogues (agonists and antagonists) of gonadotrophin-releasing hormone ( $\mathrm{GnRH})$ have been associated with a defect of the luteal phase in cycles of assisted reproduction. Furthermore, controlled ovarian stimulation was shown to be capable of accelerating endometrial maturation, hindering receptivity to embryo implantation [1]. Thus, through the years, there has been a continuous

\footnotetext{
* Correspondence: joaobatista@crh.com.br

'Department of Gynecology and Obstetrics, Botucatu Medical School São

Paulo State University - UNESP Sao Paulo, Brazil

Full list of author information is available at the end of the article
}

concern about the occurrence of luteal phase deficiency, principally in IVF/ICSI cycles [2,3], making the utilization of hCG, progesterone and sometimes estradiol (E2) a routine procedure in assisted reproduction technology (ART) to support the luteal phase. Recently, attention has been given to therapy with gonadotrophin-releasing hormone agonist (GnRH-a).

The effects of GnRH-a administration in the luteal phase has been the focus of different studies. Lemay et al. [4,5] suggested that GnRH-a can act as a luteolytic agent due to desensitization of GnRH receptors. Furthermore, Dubourdieu et al. [6] and Herman et al. [7] reported deterioration of corpus luteum function with the administration of GnRH-a. However, attempts to interrupt pregnancy or 
even prevent implantation have not been impressive [8,9]. On the other hand, a series of studies show that the inadvertent administration of $\mathrm{GnRH}-\mathrm{a}$ in the luteal phase does not compromise the continuity of pregnancy, and suggested, to the contrary, a possible favorable effect on implantation [10-14]. Recently, different studies analyzing single [15-18] or multiple administrations [19-22] of medication have, in fact, suggested a beneficial effect in supporting the luteal phase. The mechanism of the presumed beneficial effect is poorly defined. It was suggested that $\mathrm{GnRH}$-a can collaborate in the maintenance of the corpus luteum, acting directly on the endometrium via local receptors, a direct effect on the embryos or by some combination of these possibilities. On the other hand, other authors did not confirm positive action from the administration of GnRH-a in the luteal phase [23-25].

This meta-analysis aimed to evaluate the effect of the administration of single-dose GnRH-a in the luteal phase on IVF/ICSI clinical outcomes in ovarian stimulation protocols using $\mathrm{GnRH}$ antagonist (GnRH-ant) multi low-dose ovarian stimulation protocol or long $\mathrm{GnRH}-\mathrm{a}$ ovarian stimulation protocol.

\section{Methods}

\section{Criteria for considering studies for this meta-analysis}

All published and ongoing randomized controlled trials assessing the effect of single dose GnRH-a administration in luteal support on IVF/ICSI outcomes were included. Frozen embryo replacement and egg donation cycles were not included. Due to the large difference in $\mathrm{GnRH}-\mathrm{a}$ application schemes, studies with multiple applications of $\mathrm{GnRH}-\mathrm{a}$ in the luteal phase were excluded.

\section{Outcome measures}

The outcome measures used for this meta-analysis were implantation rate, clinical pregnancy rate (CPR) per transfer and ongoing pregnancy rate.

\section{Identification of studies}

Search strategies included online surveys of databases (MEDLINE, EMBASE, Science Citation Index, Cochrane Controlled Trials Register and Ovid) from 1980 to 2010. There was no language restriction. The following medical subject headings and text words were used: $\mathrm{GnRH}$ agonist, luteal phase, luteal phase support, luteal phase administration, IVF, ICSI and randomized controlled trial. The principal inclusion criterion was randomized controlled trial (RCT).

\section{Search results}

Among the 12 potentially relevant studies retrieved, a total of 5 trials fulfilled the inclusion criteria
$[15,16,18,23,24]$. A flow diagram of the selection process is shown in Fig 1.

\section{Description of the studies, validity assessment and data extraction}

Each trial was assessed independently by three reviewers (JBAO, RB and JGF) and ranked for its methodological rigor and its potential to introduce bias. Missing data were obtained from the authors when possible.

In two trials $[16,24]$ the long $\mathrm{GnRH}-\mathrm{a}$ (leuprolide: 1 , buserelin: 1) ovarian stimulation protocol starting in the mid-luteal phase of the preceding cycle was used as a reference treatment, in two $[15,23]$ the GnRH-ant (cetrorelix: 1, cetrorelix/ganirelix: 1) multi low-dose ovarian stimulation protocol was applied and in one [18] both ovarian stimulation protocol types were used. In all studies ICSI was performed. Table 1 summarizes the main characteristics of the included trails.

\section{Description of the studies}

Tesarik et al., 2006 [18] - This prospective randomized study evaluates the effect of GnRH-a administered in the luteal phase on ICSI outcomes in both GnRH-aand GnRH-ant-treated ovarian stimulation protocols. Six hundred women (300 using a long GnRH-a protocol and 300 using a GnRH-ant protocol) were enrolled. Patients treated with each of these two protocols were randomly assigned to receive a single injection of GnRH-a (0.1 mg of triptorelin) or placebo 6 days after ICSI. Irrespective of whether GnRH-a was used as luteal-phase support or not, all women were given $4 \mathrm{mg}$ of E2 valerate daily, $400 \mathrm{mg}$ of vaginal micronized progesterone daily from the day of oocyte recovery for 17 days and an injection of $250 \mu \mathrm{g}$ of HCG on the day of embryo transfer. In the results it was observed in GnRH-a-treated ovarian stimulation cycles a significant improvement of implantation and live birth in lutealphase GnRH-a group as compared with placebo. In GnRH-ant-treated ovarian stimulation cycles, lutealphase GnRH-a also increased ongoing pregnancy rate.

Ata et al., 2008 [24] - This double blind, randomized, placebo controlled trial evaluates whether a single dose GnRH-a administered 6 days after ICSI increases ongoing pregnancy rates in cycles stimulated with the long GnRH-a protocol. Five hundred and seventy women were included. In addition to routine luteal phase support with vaginal progesterone gel $(90 \mathrm{mg})$, women were randomized to receive a single $0.1 \mathrm{mg}$ dose of triptorelin or placebo 6 days after ICSI. Randomization was done on the day of ET according to a computer generated randomization table. There were 89 (31.2\%) ongoing pregnancies in the $\mathrm{GnRH}$ agonist group, and $84(29.5 \%)$ in the control group. 


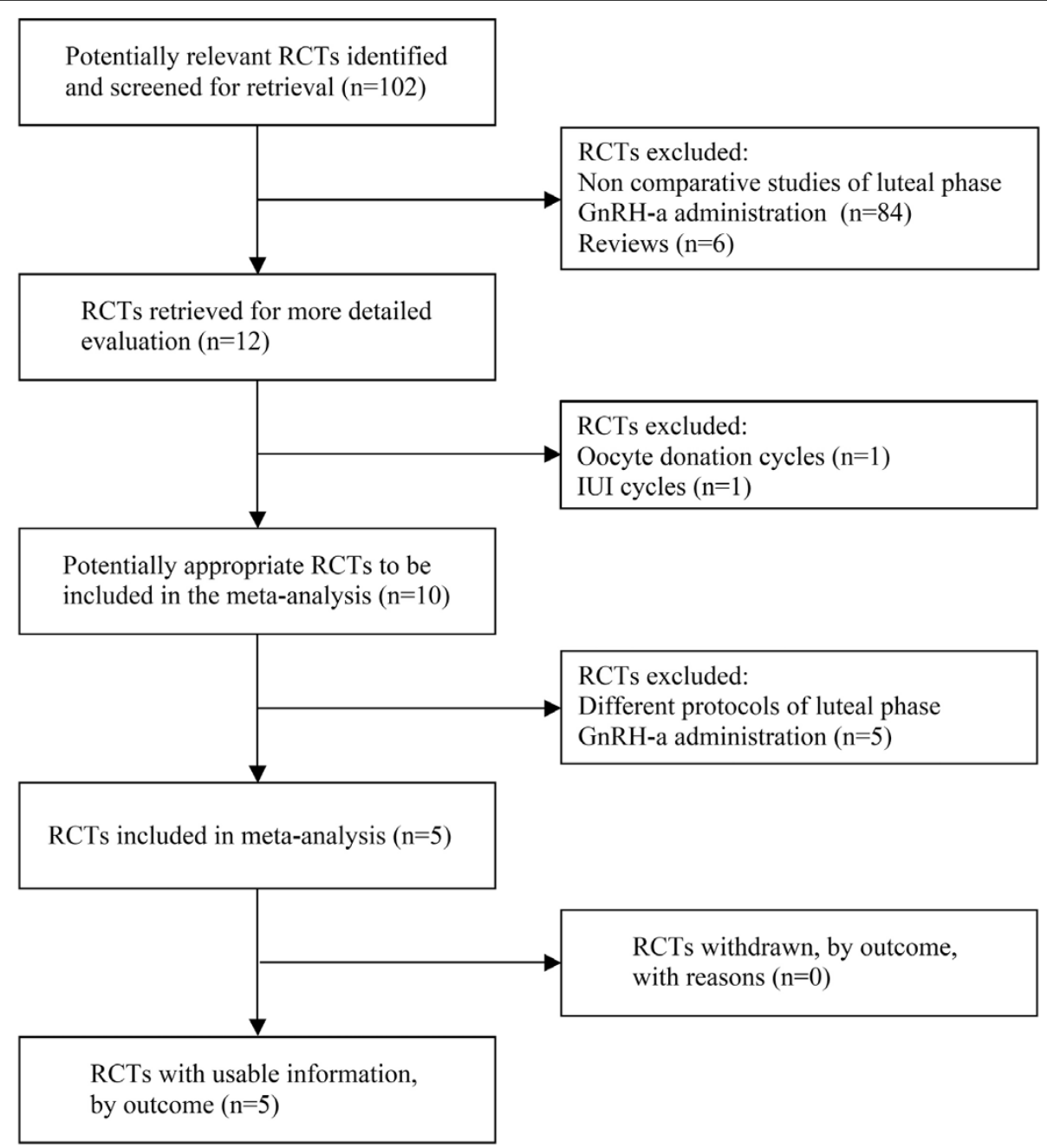

Figure 1 QUOROM statement flow diagram illustrating selection of trials included in the meta-analysis. RCT: randomized controlled trial.

Implantation, clinical pregnancy and multiple pregnancy rates were likewise similar in the GnRH agonist and placebo groups.

Isik et al., 2009 [15] - The study population consisted of 164 patients who underwent ICSI after ovulation induction by gonadotrophins and $\mathrm{GnRH}$-ant for the prevention of a premature LH surge. For luteal-phase support, all the cases received intravaginal $600 \mathrm{mg}$ micronized progesterone. In this prospective study, patients were randomly assigned to two groups. In one group, patients received an additional single dose of GnRH-a (0.5 mg leuprolide acetate) subcutaneously on day 6 after ICSI, whereas the patients in the other group did not. Although the number of embryos transferred and the grade of the embryos were similar in the two groups, the patients in the luteal-phase agonist group had significantly higher rates of implantation and clinical pregnancy rates $(\mathrm{P}<0.05)$.
Razieh et al., 2009 [16] - The aim of this study was to assess the effect of single dose GnRH-a administered 3 days after embryo transfer, as luteal phase support, on ICSI cycles stimulated with the long GnRH-a protocol. One hundred and eighty women were enrolled. Patients were randomly assigned to receive a single dose of GnRH-a (0.1 mg of triptorelin) or placebo. The luteal phase was supported by administration of progesterone $800 \mathrm{mg}$ daily in all the cases. It was observed that the patients in the luteal-phase GnRH-a group had a significant improvement in implantation rate $(12.3 \%$ vs. $7.3 \%)$ and clinical pregnancy rate $(25.5 \%$ vs. $10.0 \%)$ as compared with placebo.

Ata and Urman, 2010 [23] - This trial evaluated whether a single dose GnRH-a administered 6 days after ICSI increases ongoing pregnancy rates in cycles stimulated with the long GnRH-ant protocol. Ninety women were included. In addition to routine luteal phase 
Table 1 Main characteristics of randomized controlled trials (RCT) on the use of GnRH in luteal phase

\begin{tabular}{|c|c|c|c|c|c|c|}
\hline \multirow[t]{2}{*}{ Trial } & \multirow[t]{2}{*}{ Randomization } & \multirow[t]{2}{*}{ Protocol stimulation } & \multicolumn{3}{|l|}{ Luteal Phase } & \multirow[t]{2}{*}{ Results } \\
\hline & & & $\begin{array}{l}\text { Study group } \\
\text { GnRH-a }\end{array}$ & $\begin{array}{l}\text { Control } \\
\text { group }\end{array}$ & $\begin{array}{l}\text { Others medicines } \\
\text { (all patients) }\end{array}$ & \\
\hline $\begin{array}{l}\text { Tesarik et al., } \\
2006[18]\end{array}$ & $\begin{array}{l}\text { Embryo transfer } \\
\text { day } \\
\text { Computer } \\
\text { generated list } \\
\text { Opaque envelopes } \\
\text { Blinding }\end{array}$ & $\begin{array}{l}\text { GnRH-a long protocol/ } \\
\text { GnRH-ant multiple dose } \\
+ \\
\text { r-FSH/HMG } \\
+ \\
r-H C G\end{array}$ & $\begin{array}{l}\text { n:150 GnRH-a } \\
\text { long protocol) } \\
\text { n:150 GnRH-ant } \\
\text { protocol } \\
\text { Single injection } \\
\text { Dose:0.1 mg/ } \\
\text { triptorelin } \\
\text { Day } 6 \text { after ICSI }\end{array}$ & $\begin{array}{l}\text { n:150 } \\
\text { (GnRHa- } \\
\text { long } \\
\text { protocol) } \\
\text { n:150 } \\
\text { (Antagonist } \\
\text { protocol) } \\
\text { Placebo }\end{array}$ & $\begin{array}{l}\text { E2 valerate }(4 \mathrm{mg}) \\
+ \\
\text { Vaginal micronized } \\
\text { progesterone( } 400 \mathrm{mg}) \\
+ \\
\mathrm{r}-\mathrm{HCG} \text { (single dose) }\end{array}$ & $\begin{array}{l}\text { Improvement implantation/ } \\
\text { live birth rates }\end{array}$ \\
\hline $\begin{array}{l}\text { Ata et al., } \\
2008 \text { [24] }\end{array}$ & $\begin{array}{l}\text { Embryo transfer } \\
\text { day } \\
\text { Computer } \\
\text { generated list } \\
\text { Opaque envelopes } \\
\text { Blinding }\end{array}$ & $\begin{array}{l}\text { GnRH-a long protocol } \\
+ \\
r-F S H \\
+ \\
+ \\
\text { HCG }\end{array}$ & $\begin{array}{l}\mathrm{n}: 285 \\
\text { Single injection } \\
\text { Dose:0.1 mg/ } \\
\text { triptorelin } \\
\text { Day } 6 \text { after ICSI }\end{array}$ & $\begin{array}{l}\text { n:285 } \\
\text { Placebo }\end{array}$ & $\begin{array}{l}\text { Vaginal progesterone } \\
\text { gel/90 mg }\end{array}$ & No differences \\
\hline $\begin{array}{l}\text { Isik et al., } \\
2009 \text { [15] }\end{array}$ & $\begin{array}{l}\text { Embryo transfer } \\
\text { day } \\
\text { Computer } \\
\text { generated list } \\
\text { Blinding }\end{array}$ & $\begin{array}{l}\text { GnRH-ant multiple dose } \\
+ \\
\mathrm{r}-\mathrm{FSH} / \mathrm{HMG} \\
+ \\
\mathrm{hCG} / \mathrm{r}-\mathrm{hCG}\end{array}$ & $\begin{array}{l}\mathrm{n}: 74 \\
\text { Single injection } \\
\text { Dose:0.5 mg/ } \\
\text { leuprolide } \\
\text { Day } 6 \text { after ICSI }\end{array}$ & $\begin{array}{l}\text { n:80 } \\
\text { No placebo }\end{array}$ & $\begin{array}{l}\text { Vaginal micronized } \\
\text { progesterone }(600 \text { mg) } \\
+ \\
+ \\
\text { HCG(single dose) }\end{array}$ & $\begin{array}{l}\text { Improvement implantation/ } \\
\text { clinical pregnancy rates }\end{array}$ \\
\hline $\begin{array}{l}\text { Razieh et al., } \\
2009 \text { [16] }\end{array}$ & $\begin{array}{l}\text { Drawing piece of } \\
\text { paper from a bag }\end{array}$ & $\begin{array}{l}\text { GnRH-a long protocol } \\
+ \\
r-\mathrm{FSH} \\
+ \\
\mathrm{HCG}\end{array}$ & $\begin{array}{l}\mathrm{n}: 90 \\
\text { Single injection } \\
\text { Dose: } 0.1 \mathrm{mg} / \\
\text { triptorelin } \\
\text { Day } 5 / 6 \text { after } \\
\text { ICSI }\end{array}$ & $\begin{array}{l}\text { n:90 } \\
\text { Placebo }\end{array}$ & $\begin{array}{l}\text { Vaginal micronized } \\
\text { progesterone(800 mg) }\end{array}$ & $\begin{array}{l}\text { Improvement implantation/ } \\
\text { clinical pregnancy rates }\end{array}$ \\
\hline $\begin{array}{l}\text { Ata and } \\
\text { Urman, } 2010 \\
\text { [23] }\end{array}$ & $\begin{array}{l}\text { Embryo transfer } \\
\text { day } \\
\text { Computer } \\
\text { generated list } \\
\text { Opaque envelopes } \\
\text { Blinding }\end{array}$ & $\begin{array}{l}\text { GnRH-ant multiple dose } \\
+ \\
r-\mathrm{FSH} / \mathrm{HMG} \\
+ \\
\mathrm{r}-\mathrm{HCG}\end{array}$ & $\begin{array}{l}\mathrm{n}: 38 \\
\text { Single injection } \\
\text { Dose:0.1 mg/ } \\
\text { triptorelin } \\
\text { Day } 6 \text { after ICSI }\end{array}$ & $\begin{array}{l}\text { n:52 } \\
\text { Placebo }\end{array}$ & $\begin{array}{l}\text { Vaginal progesterone } \\
\text { gel/90 mg }\end{array}$ & $\begin{array}{l}\text { Lower Implantation/ } \\
\text { ongoing pregnancy rates }\end{array}$ \\
\hline
\end{tabular}

support with vaginal progesterone gel $(90 \mathrm{mg})$, women were randomized to receive a single $0.1 \mathrm{mg}$ dose of triptorelin or placebo 6 days after ICSI. In the results it was observed a significant reduction in implantation and ongoing pregnancy rates in luteal GnRH-a group as compared with placebo. Clinical pregnancy rates were similar in the GnRH-a and placebo groups.

\section{Statistical analysis}

Data management and analysis were conducted using the StatsDirect statistical software (Cheshire, UK). The fixed effect model was used for odds ratio (OR) and the effectiveness was evaluated by the Mantel-Haenszel method. A confidence interval (CI) was calculated using the variance formula of Robins, Breslow and Greenland. A chi-squared test statistic was used with its associated probability that the pooled OR was equal to 1 . The measure of heterogeneity (non-combinability) was evaluated by Cochran's Q, the Breslow-Day and $\mathrm{I}^{2}$ tests. A nonsignificant result (i.e. lack of heterogeneity) indicates that no trial had an OR significantly worse or better than the overall common OR obtained by pooling the data. Since a fixed effects model has been employed herein, it is important to acknowledge that inferences refer only to the particular studies included in the analysis. Meta-analysis used in this manner is simply a device to pool the information from the various studies to provide a composite finding, but only for those studies. Since many of the preceding analyses contained only two or three studies, it was decided to derive the inferences from a fixed-effects model.

\section{Results}

Implantation rate (Fig 2)

Four studies were included $[15,18,23,24]$. The pooled implantation rate was significantly higher in the group of patients that received GnRH-a in the luteal phase $(24.4 \%, 411 / 1686)$ than in the group that did not receive this hormone agonist $(18.6 \%, 335 / 1798)(\mathrm{P}<0.0001$; OR $=1.40,95 \%$ CI $1.19,1.65)$. There was heterogeneity in this comparison (Breslow-Day $=31.52$, $\mathrm{df}=3, \mathrm{P}<$ 0.0001; Cochran $\mathrm{Q}=30.40, \mathrm{df}=3, \mathrm{P}<0.0001 ; \mathrm{I}^{2}=$ $90.1 \%, 95 \% \mathrm{CI}=75.6 \%$ to $94.5 \%)$.

In the subgroup of trials where the long GnRH-a ovarian stimulation protocol was used [18,24], the pooled implantation rate was significantly greater in the group of patients that received GnRH-a in the luteal phase $(24 \%, 259 / 1080)$ than in the group that did not 


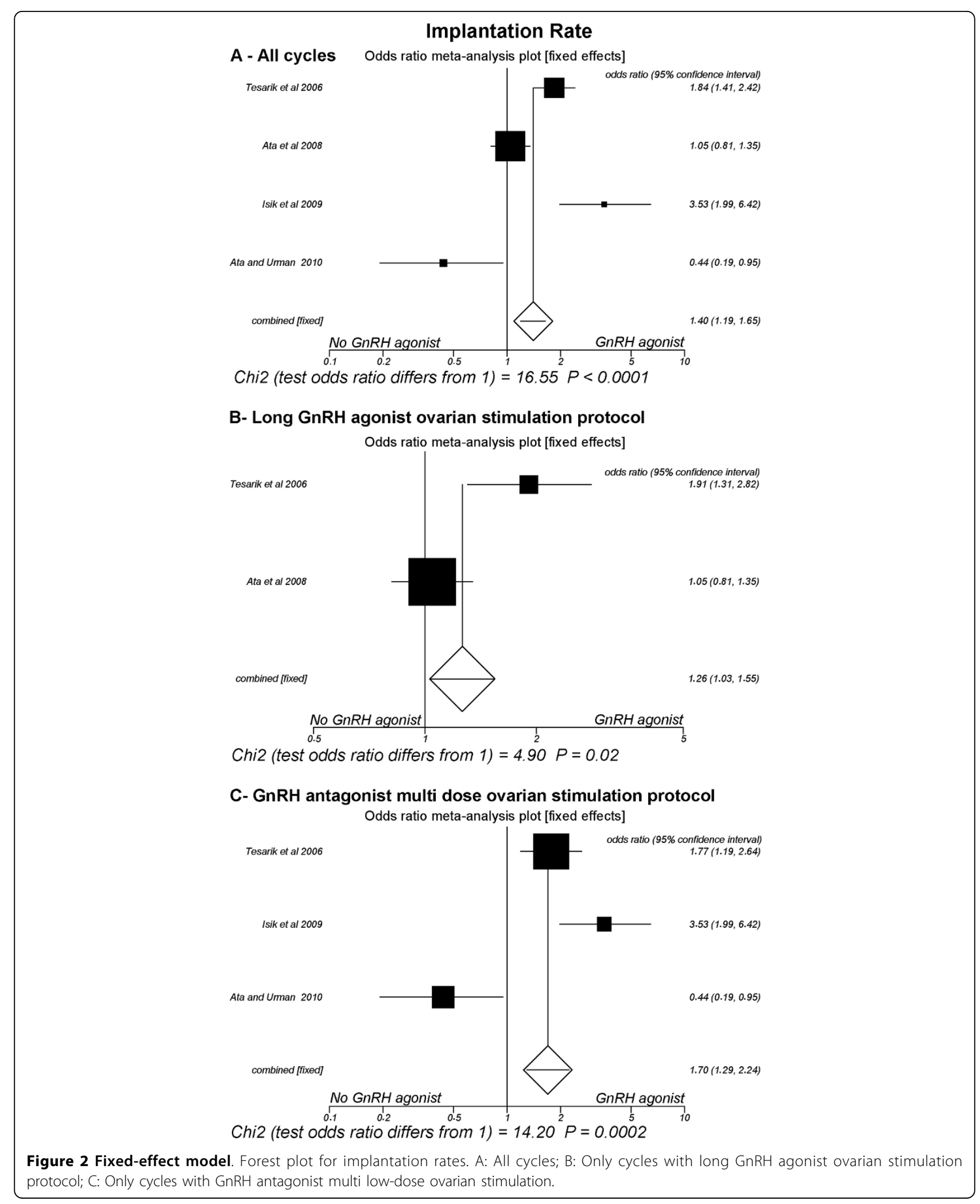


receive it $(20 \%, 224 / 1122)(\mathrm{P}=0.02$; OR $=1.26,95 \% \mathrm{CI}$ $1.03,1.54)$. There was heterogeneity in this comparison (Breslow-Day $=7.25, \mathrm{df}=1, \mathrm{P}=0.007$; Cochran $\mathrm{Q}=$ 7.21 , df $=1, P=0.007)$. Similarly, in the subgroup of trials where the GnRH-ant multi low-dose ovarian stimulation protocol was used $[15,18,23]$, the pooled implantation rate was also significantly higher in the group of patients that received $\mathrm{GnRH}-\mathrm{a}$ in the luteal phase $(25.1 \%, 152 / 606)$ than in the group not administered this substance $(16.4 \%, 111 / 676)(\mathrm{P}=0.0002 ; \mathrm{OR}=$ $1.70,95 \%$ CI $1.29,2.23)$. There was heterogeneity in this comparison (Breslow-Day $=20.46, \mathrm{df}=2, \mathrm{P}<0.0001$; Cochran $\mathrm{Q}=20.17$, df $=2, \mathrm{P}<0.0001 ; \mathrm{I}^{2}=90.1 \%, 95 \%$ $\mathrm{CI}=66.9 \%$ to $95 \%$ )

\section{Clinical pregnancy rate per transfer (Fig 3)}

Five studies were included $[15,16,18,23,24]$. The pooled CPR per transfer was significantly higher in the group of patients administered GnRH-a in the luteal phase $(42.4 \%, 328 / 773)$ than in the group that did not receive it $(35.7 \%, 283 / 793)(\mathrm{P}=0.006$; OR $=1.33,95 \% \mathrm{CI} 1.08$, 1.64). There was heterogeneity in this comparison (Breslow-Day $=15.65, \mathrm{df}=4, \mathrm{P}=0.003$; Cochran $\mathrm{Q}=15.32$, $\mathrm{df}=4, \mathrm{P}=0.004 ; \mathrm{I}^{2}=73.9 \%, 95 \% \mathrm{CI}=0 \%$ to $87.5 \%$ ).

However, in the subgroup of trials where the long GnRH-a ovarian stimulation protocol was used $[16,18,24]$, the pooled CPR per transfer did not differ significantly between the group of patients that received GnRH-a in the luteal phase $(42 \%, 217 / 516)$ versus the group that did not receive it $(36.4 \%, 188 / 517)(\mathrm{P}=0.06$; $\mathrm{OR}=1.28,95 \%$ CI $0.99,1.65)$, a comparison with heterogeneity (Breslow-Day $=6.42, \mathrm{df}=2, \mathrm{P}=0.04$; Cochran $\mathrm{Q}=6.25, \mathrm{df}=2, \mathrm{P}=0.04 ; \mathrm{I}^{2}=68 \%, 95 \% \mathrm{CI}=$ $0 \%$ to $88.6 \%)$. On the other hand, in the subgroup of trials where the GnRH-ant ovarian stimulation protocol was used $[15,18,23]$, the CPR per transfer was significantly higher in the group of patients that received GnRH-a in the luteal phase $(43.2 \%, 111 / 257)$ than in the group that were not administered this hormone agonist $(34.4 \%, 95 / 276)(\mathrm{P}=0.04$; OR $=1.44,95 \%$ CI 1.01 , $2.05)$. There was heterogeneity in this comparison (Breslow-Day $=8.94, \mathrm{df}=2, \mathrm{P}=0.01 ;$ Cochran $\mathrm{Q}=8.74, \mathrm{df}$ $=2, \mathrm{P}=0.01 ; \mathrm{I}^{2}=77.1 \%, 95 \% \mathrm{CI}=0 \%$ to $90.9 \%$ )

\section{Ongoing pregnancy rate (Fig 4)}

Four studies were included $[15,18,23,24]$. The pooled ongoing pregnancy rate was significantly greater in the group of patients that received GnRH-a in the luteal phase $(37 \%, 253 / 683)$ than in the group that did not receive it $(31.1 \%, 219 / 703)(\mathrm{P}=0.02$; OR $=1.29,95 \% \mathrm{CI}$ $1.03,1.62$ ), a heterogeneous comparison (Breslow-Day = 14.94, $\mathrm{df}=3, \mathrm{P}=0.001$; Cochran $\mathrm{Q}=14.23$, $\mathrm{df}=3, \mathrm{P}=$ $0.002 ; \mathrm{I}^{2}=78.9 \%, 95 \% \mathrm{CI}=7.9 \%$ to $\left.90.2 \%\right)$.
However, in the subgroup of trials where the long $\mathrm{GnRH}-\mathrm{a}$ ovarian stimulation protocol was used $[18,24]$, the pooled ongoing pregnancy rate was not significantly different between the patients that received $(36.4 \%, 155 / 426)$ versus the group that did not receive GnRH-a in the luteal phase $(32.3 \%, 138 / 427)(\mathrm{P}=0.23$; $\mathrm{OR}=1.20$, 95\% CI 0.90, 1.59). There was no heterogeneity in this comparison (Breslow-Day $=0.84, \mathrm{df}=1$, $\mathrm{P}=0.35$; Cochran $\mathrm{Q}=0.84$, $\mathrm{df}=3, \mathrm{P}=0.25$ ). On the other hand, in the subgroup of trials where the GnRHant ovarian stimulation protocol was used [15,18,23], the pooled ongoing pregnancy rate was significantly elevated in the group of patients that received $\mathrm{GnRH}$-a in the luteal phase $(38.1 \%, 98 / 257)$ in relation to the group that did not receive it $(29.3 \%, 81 / 276)(\mathrm{P}=0.04$; $\mathrm{OR}=1.46,95 \% \mathrm{CI} 1.02,2.10)$, a comparison with heterogeneity (Breslow-Day $=13.6$, $\mathrm{df}=2, \mathrm{P}=0.001$; Cochran $\mathrm{Q}=12.7, \mathrm{df}=2, \mathrm{P}=0.001 ; \mathrm{I}^{2}=84.4 \%, 95 \%$ $\mathrm{CI}=16.9 \%$ to $93.1 \%)$.

\section{Discussion}

The increasing volume of information has stimulated a growing need for reviews of the medical literature. Meta-analysis differs from the narrative review by its rigorous and complete quantitative and qualitative methodological approaches. It is an analytical approach where different and independent studies are integrated and the results combined into a unique common result. When it is compared with narrative review, meta-analysis has the great advantage of being less influenced by the personal opinion of the reviewer thus providing impartial conclusions. Moreover, all of the results can easily be recalculated and compared with the authors' conclusions. The meta-analysis, even when not producing definite conclusions about the utility of a treatment, can support the necessity for new randomized trials on the subject. Different RCTs evaluating the effects of luteal GnRH-a administration on clinical outcomes have been published recently but with divergent conclusions $[15,16,18,23,24]$. Therefore, given the clinical potential of this practise, a review about this subject would seem to be helpful.

It has been suggested that a meta-analysis should be patient oriented, i.e. primary outcomes should be clinical results, which predict a better outcome and/or a more advantageous cost/effectiveness ratio. In this type of meta-analysis, GnRH-a administration in the luteal phase produced a favorable effect not only on the general implantation rate but also on the implantation rate for both subgroups. In addition, luteal GnRH-a treatment produced a significantly higher clinical pregnancy rate in the group administered the $\mathrm{GnRH}$-ant multidose ovarian stimulation protocol. On the basis of these 


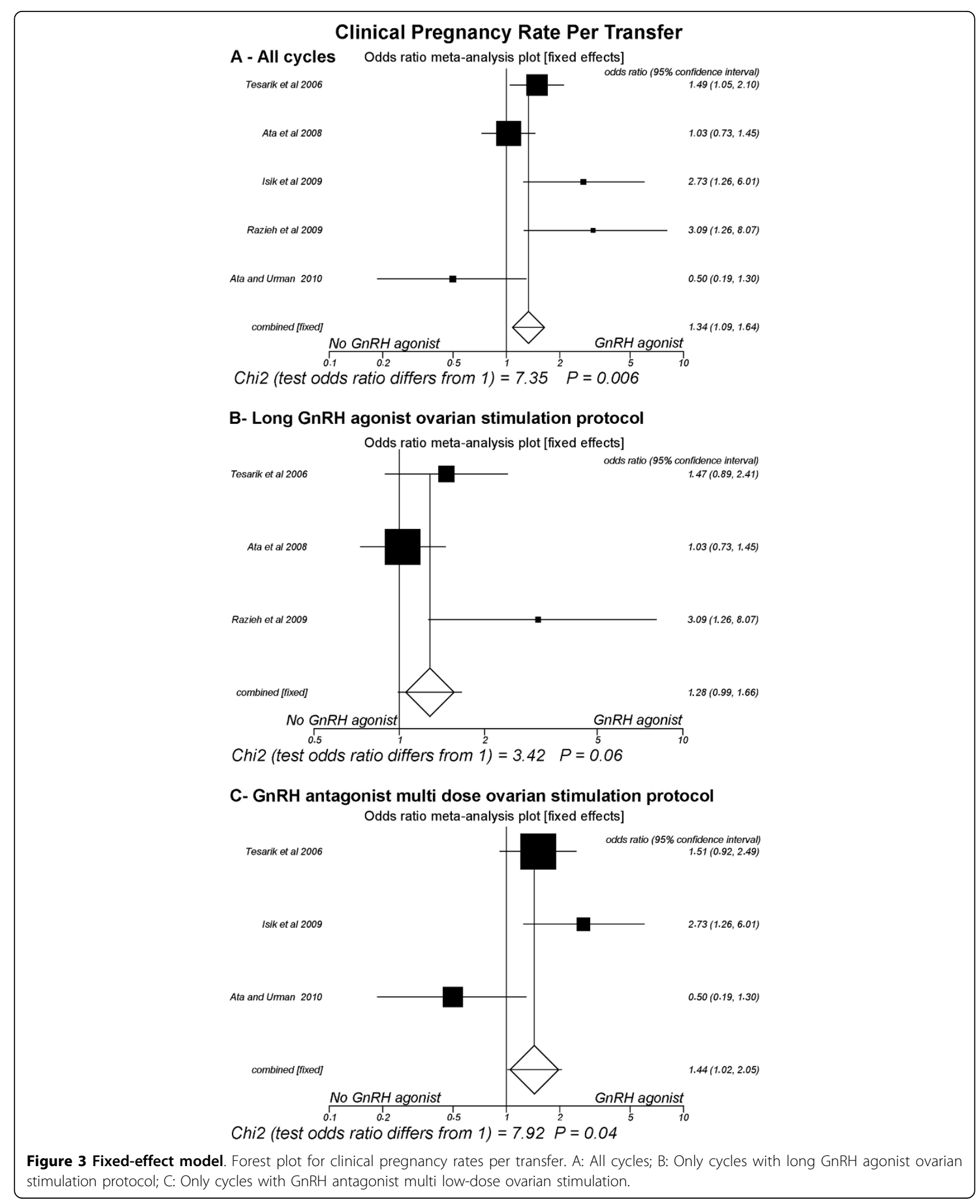




\section{Ongoing Pregnancy Rate}

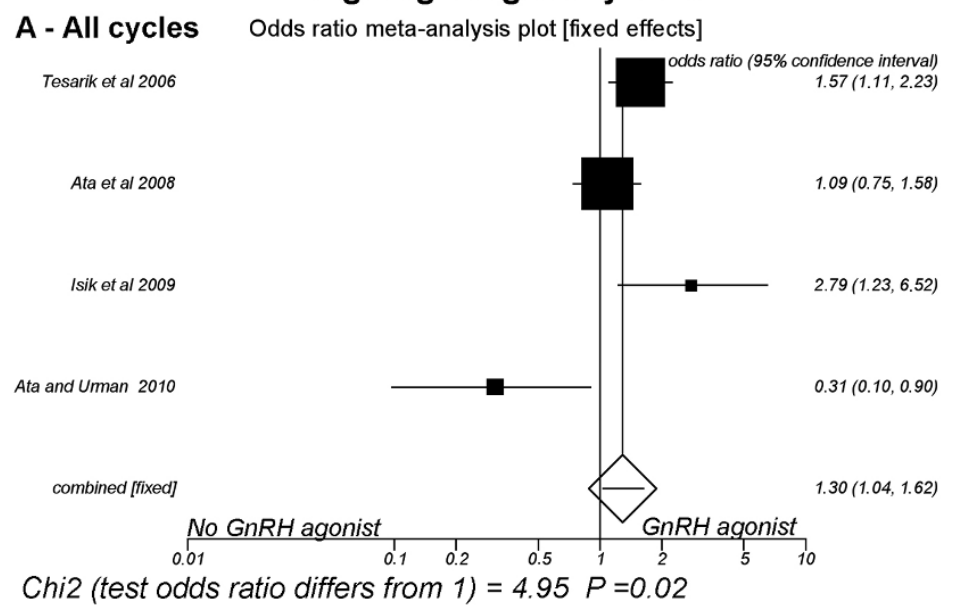

\section{B- Long GnRH agonist ovarian stimulation protocol}

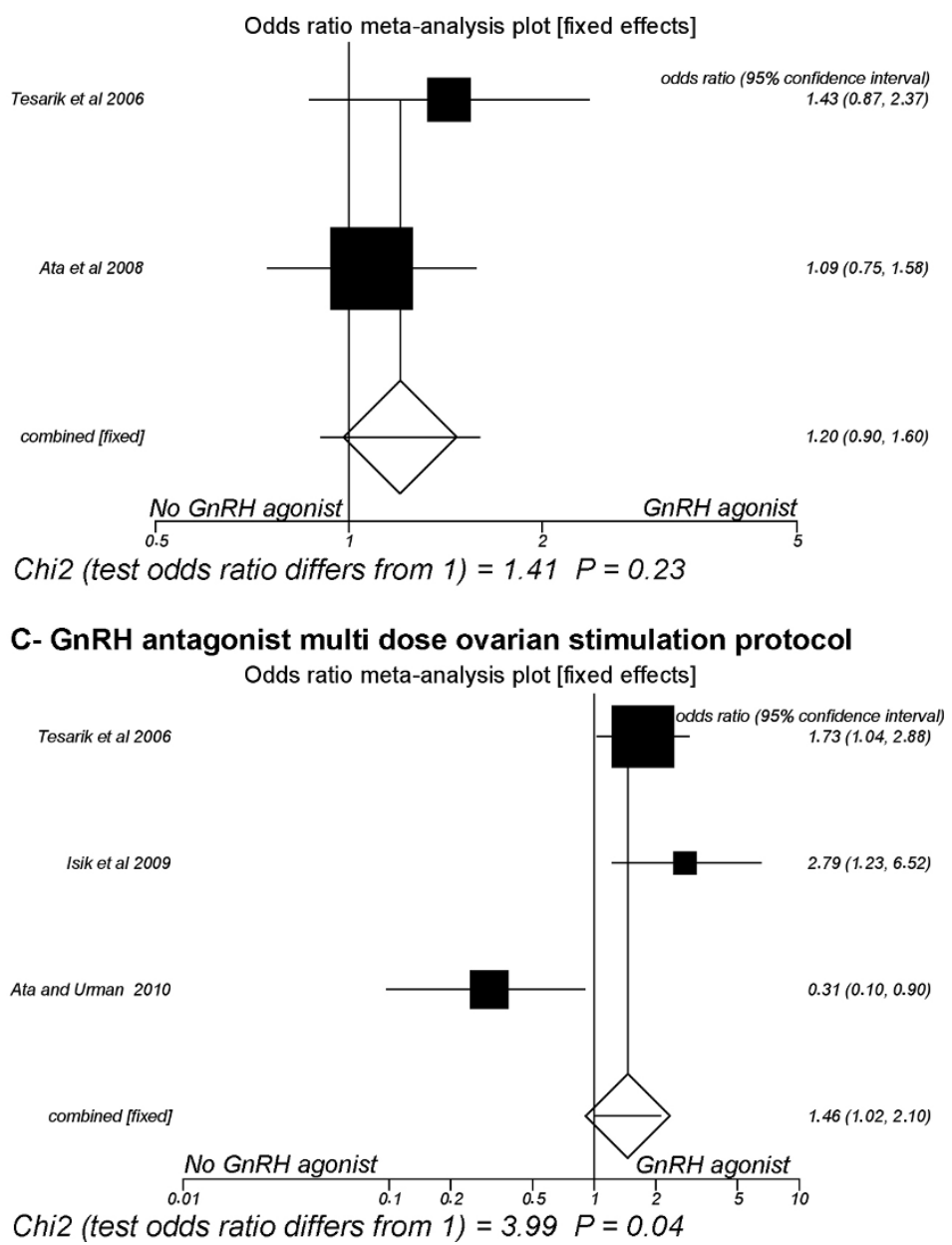

Figure 4 Fixed-effect model. Ongoing clinical pregnancy rates. A: All cycles; B: Only cycles with long GnRH agonist ovarian stimulation protocol; C: Only cycles with $\mathrm{GnRH}$ antagonist multi low-dose ovarian stimulation. 
data, it may seem attractive to consider administration of a single dose of GnRH-a in the IVF/ICSI luteal phase to improve clinical outcomes, especially in $\mathrm{GnRH}$ antagonist cycles. Other RCTs not included in this meta-analysis $[19,20]$ yielded the same results. Although these trials were performed in different conditions (GnRH agonist administration was continued until 14 days after oocyte retrieval; GnRH agonist administration on the day of ovum pickup, on the day of embryo transfer and three days thereafter, respectively), their outcomes are clearly consistent with those of this metaanalysis (i.e. increase in implantation rate) and support the hypothesis that $\mathrm{GnRH}$-a administration in luteal phase may be useful.

Nevertheless, meta-analysis also presents problems. Heterogeneity and insufficient power (low sample size) hinder the ability to draw inferences about the metaanalysis, which failed to show any statistically significant difference in the clinical pregnancy rate and ongoing (in GnRH-a long protocol cycles) pregnancy rate. This observation can be related to a small cumulative sample size. In the long GnRH-a ovarian stimulation protocol, based on the CPR per transfer obtained in the groups with and without luteal GnRH-a (42\%, 217/516 and $36.4 \%, 188 / 517)$, the ability to detect a difference of $5 \%$ with a power of $80 \%$ would require around 2450 patients to reach a definitive conclusion, i.e. a sample size above the total number included. Similarly, still In the long $\mathrm{GnRH}-\mathrm{a}$ ovarian stimulation protocol, based on the ongoing pregnancy rates obtained in the groups with and without luteal GnRH-a (36.4\%, 155/426 and $32.3 \%, 138 / 427)$, detecting a $5 \%$ difference with $80 \%$ power would require around 4300 patients to draw a definitive conclusion. Thus, for a more consistent conclusion, this meta-analysis guides researchers to wait for the results of new RCTs that have more information about clinical parameters.

One must be aware of the fact that a number of other significant predictors of the outcomes exist in an individual patient. Given that heterogeneity was observed in most of the comparisons carried out in this meta-analysis, a detailing of these studies should be made. Tesarik et al. [18] asserts that the effect of luteal-phase GnRH agonist administration should be interpreted in the context of luteal-phase support. However, it can be seen that the luteal phases were differently managed among the trials: Tesarik et al. [18]: Vaginal micronized progesterone $(400 \mathrm{mg})+\mathrm{r}$-HCG (single dose) $+\mathrm{E} 2$ valerate; Ata et al [24] and Ata and Urman [23]: Vaginal progesterone gel/90 mg; Isik et al. [15]: Vaginal micronized progesterone $(600 \mathrm{mg})+$ HCG(single dose); Razieh et al. [16]: Vaginal micronized progesterone $(800 \mathrm{mg})$. This difference among the populations may have contributed to the divergent results obtained and, consequently, to the heterogeneity observed in this meta-analysis. Again, future controlled trials will clarify this issue.

The beneficial effects on clinical variables observed herein, despite the differences in the luteal-phase background, and the fact the drug can be easily prescribed, make the possibility of administering GnRH-a in ICSI luteal phase support appear more attractive. However, there is a need for discussion regarding the possible mechanisms of GnRH-a luteal action. The hypothesis that $\mathrm{GnRH}$-a exerts a direct beneficial effect on the embryos [17] is supported by different observations. Animal experiments suggest that GnRH-a can improve the in vitro development of the embryo [26-29]. In addition, GnRH appears to exert regulatory activity in the synthesis and secretion of HCG by pre-implanted embryos and by the placenta [30,31]. Tesarik et al. [18] suggest possible direct effects on the embryo on account of observation of higher levels of serum 3 -HCG in the overall group of patients who achieved a pregnancy after luteal-phase administration of $\mathrm{GnRH}-\mathrm{a}$ as compared with placebo. On the other hand, given that the medication is administered in the presence of the embryos, such improvement in clinical outcomes should be carefully weighed against possible harmful effects on the health of resulting children. The relatively secure notion that exposure of embryos to GnRH-a is not prejudicial is based on a series of case reports on its accidental administration to pregnant women that, in general, report only on early postnatal examination of the children [10-14]. Thus, further long-term follow-ups of such children are still necessary to elucidate this point.

A direct action on uterine tissue may also be responsible for the effects of GnRH-a in the luteal phase. A presence of GnRH receptor with a dynamic pattern (more intense in the luteal phase) was demonstrated in human endometrium both in the epithelium and stroma [32-34]. Moreover, it has been also reported that GnRH and $\mathrm{GnRH}-\mathrm{a}$ can alter the activity of matrix metalloproteinases, involved in tissue remodeling (matrix degradation) inherent to the process of endometrial trophoblast invasion [35,36], and induce apoptosis in endometrial cells in vitro $[37,38]$. However, in vitro GnRH analogues do not seem to have significant influence on the extent of decidualization of endometrial stromal cells in vitro [32] nor do they have major direct effects on gene expression of human endometrial epithelial cells [39]. Thus, despite the studies suggesting a direct action on endometrial function, clinically relevant endometrial effects of the GnRH analogues still need to be established.

The corpus luteum is another possible GnRH-a target in the luteal phase, though it is questioned whether such action would occur through the secretion of pituitary hormones or by direct action in the ovary. In cycles with 
GnRH-ant it is speculated that stimulation of corpus luteum activity by $\mathrm{GnRH}$-a may result from stimulation of LH secretion, given that, despite the blockade, the pituitary remains responsive to the administration of $\mathrm{GnRH}$ or GnRH-a [15]. By contrary reasoning, in the long GnRH-a ovarian stimulation protocol, such action would likely be directly on the corpus luteus, since the pituitary blockade may still be present at the moment of GnRH-a administration [24]. In any case, independent of the probable action mechanism, Tesarik et al. [18] observed under both protocols, long GnRH-a ovarian stimulation or GnRH-ant multi low-dose ovarian stimulation, the increase in serum concentrations of E2 and progesterone in the luteal phase of patients that received GnRH-a 6 days after ICSI relative to those that were administered a placebo. Nevertheless, Hugues et al. [40], in GnRH-ant cycles, observed no differences in the hormonal profile of the luteal phase after GnRH-a administration.

In conclusion, the findings of this meta-analysis demonstrate that the luteal-phase single-dose GnRH-a administration can improve clinical outcomes after ICSI. However, by considering the heterogeneity between the trials, it seems premature to recommend the use of GnRH-a in the luteal phase. Additional randomized controlled trials are necessary before evidence-based recommendations can be provided. Protocols, safety, side effects and exact action mechanism(s) should de analyzed before the adoption of $\mathrm{GnRH}-\mathrm{a}$ administration in the luteal phase.

\section{Acknowledgements}

The authors wish to thank the Research Support Group - UNESP for revising the English text.

\section{Author details}

${ }^{1}$ Department of Gynecology and Obstetrics, Botucatu Medical School São Paulo State University - UNESP Sao Paulo, Brazil. ${ }^{2}$ Center for Human Reproduction Prof. Franco Jr., Ribeirao Preto, Sao Paulo, Brazil. ${ }^{3}$ Paulista Center for Diagnosis Research and Training, Ribeirao Preto, Sao Paulo, Brazil.

\section{Authors' contributions}

JBAO was responsible for designing and coordinating the study. All authors were responsible for data collection, data analysis, and data interpretation in the manuscript. JBAO, RB, MC and JF were responsible for the statistical work and for writing the manuscript. JF was responsible for reviewing the manuscript. All authors read and approved the final manuscript.

\section{Competing interests}

The authors declare that they have no competing interests.

Received: 29 July 2010 Accepted: 8 September 2010

Published: 8 September 2010

\section{References}

1. Devroey P, Bourgain C, Macklon NS, Fauser BC: Reproductive biology and IVF: ovarian stimulation and endometrial receptivity. Trends Endocrinol Metab 2004, 15:84-90.

2. Fatemi HM, Popovic-Todorovic B, Papanikolaou E, Donoso P, Devroey P: An update of luteal phase support in stimulated IVF cycles. Hum Reprod Update 2007, 13:581-590
3. Pritts EA, Atwood AK: Luteal phase support in infertility treatment: a meta-analysis of the randomized trials. Hum Reprod 2002, 17:2287-2299.

4. Lemay A, Faure N, Labrie F: Sensitivity of pituitary and corpus luteum responses to single intranasal administration of (D-ser[TBU]6-des-gly$\mathrm{NH} 2(10))$ luteinizing hormone-releasing hormone ethylamide (Buserelin) in normal women. Fertil Steril 1982, 37:193-200.

5. Lemay A, Faure N, Labrie F, Fazekas AT: Gonadotroph and corpus luteum responses to two successive intranasal doses of a luteinizing hormonereleasing hormone agonist at different days after the midcycle luteinizing hormone surge. Fertil Steril 1983, 39:661-667.

6. Dubourdieu S, Charbonnel B, Massai MR, Marraoui J, Spitz I, Bouchard P: Suppression of corpus luteum function by the gonadotropin-releasing hormone antagonist Nal-Glu: effect of the dose and timing of human chorionic gonadotropin administration. Fertil Steril 1991, 56:440-445.

7. Herman A, Ron-El R, Golan A, Nachum H, Soffer Y, Caspi E: Impaired corpus luteum function and other undesired results of pregnancies associated with inadvertent administration of a long-acting agonist of gonadotrophin-releasing hormone. Hum Reprod 1992, 7:465-468.

8. Nillius SJ: Luteinizing hormone releasing hormone analogues for contraception. Clin Obstet Gynaecol 1984, 11:551-572.

9. Thau RB: Luteinizing hormone-releasing hormone (LHRH) and its analogs for contraception in women: a review. Contraception 1984, 29:143-162.

10. Balasch J, Martinez F, Jove I, Cabre L, Coroleu B, Barri PN, Vanrell JA: Inadvertent gonadotrophin-releasing hormone agonist ( $\mathrm{GnRHa}$ ) administration in the luteal phase may improve fecundity in in-vitro fertilization patients. Hum Reprod 1993, 8:1148-1151.

11. Cahill DJ, Fountain SA, Fox R, Fleming CF, Brinsden PR, Hull MG: Outcome of inadvertent administration of a gonadotrophin-releasing hormone agonist (buserelin) in early pregnancy. Hum Reprod 1994, 9:1243-1246.

12. Papanikolaou EG, Platteau P, Albano C, Kolibianakis E, Devroey P: Achievement of pregnancy three times in the same patient during luteal GnRH agonist administration. Reprod Biomed Online 2005, 10:347-349.

13. Platteau P, Gabbe M, Talbot M, Healy D: Two consecutive pregnancies during inadvertent gonadotropin-releasing hormone agonist desensitization. Fertil Steril 2000, 73:1244-1246.

14. Tan HH, Yeong CT, Loh KE: Perinatal outcome of pregnancies after inadvertent exposure to gonadotrophin-releasing hormone analogue. Aust N Z J Obstet Gynaecol 2006, 46:336-340.

15. Isik AZ, Caglar GS, Sozen E, Akarsu C, Tuncay G, Ozbicer T, Vicdan K: Singledose $\mathrm{GnRH}$ agonist administration in the luteal phase of $\mathrm{GnRH}$ antagonist cycles: a prospective randomized study. Reprod Biomed Online 2009, 19:472-477.

16. Razieh DF, Maryam AR, Nasim T: Beneficial effect of luteal-phase gonadotropin-releasing hormone agonist administration on implantation rate after intracytoplasmic sperm injection. Taiwan J Obstet Gynecol 2009, 48:245-248.

17. Tesarik J, Hazout A, Mendoza C: Enhancement of embryo developmental potential by a single administration of $\mathrm{GnRH}$ agonist at the time of implantation. Hum Reprod 2004, 19:1176-1180.

18. Tesarik J, Hazout A, Mendoza-Tesarik R, Mendoza N, Mendoza C: Beneficial effect of luteal-phase GnRH agonist administration on embryo implantation after ICSI in both GnRH agonist- and antagonist-treated ovarian stimulation cycles. Hum Reprod 2006, 21:2572-2579.

19. Fujii S, Sato S, Fukui A, Kimura H, Kasai G, Saito Y: Continuous administration of gonadotrophin-releasing hormone agonist during the luteal phase in IVF. Hum Reprod 2001, 16:1671-1675.

20. Qublan H, Amarin Z, Al-Qudah M, Diab F, Nawasreh M, Malkawi S, Balawneh M: Luteal phase support with $\mathrm{GnRH}-\mathrm{a}$ improves implantation and pregnancy rates in IVF cycles with endometrium of <or $=7 \mathrm{~mm}$ on day of egg retrieval. Hum Fertil (Camb) 2008, 11:43-47.

21. Pirard C, Donnez J, Loumaye E: GnRH agonist as novel luteal support: results of a randomized, parallel group, feasibility study using intranasal administration of buserelin. Hum Reprod 2005, 20:1798-1804.

22. Pirard C, Donnez J, Loumaye E: GnRH agonist as luteal phase support in assisted reproduction technique cycles: results of a pilot study. Hum Reprod 2006, 21:1894-1900.

23. Ata B, Urman B: Single dose GnRH agonist administration in the luteal phase of assisted reproduction cycles: is the effect dependent on the type of GnRH analogue used for pituitary suppression? Reprod Biomed Online 2010, 20:165-166. 
24. Ata B, Yakin K, Balaban B, Urman B: GnRH agonist protocol administration in the luteal phase in ICSI-ET cycles stimulated with the long GnRH agonist protocol: a randomized, controlled double blind study. Hum Reprod 2008, 23:668-673.

25. Isikoglu M, Ozgur K, Oehninger S: Extension of GnRH agonist through the luteal phase to improve the outcome of intracytoplasmic sperm injection. J Reprod Med 2007, 52:639-644.

26. Casan EM, Raga F, Polan ML: GnRH mRNA and protein expression in human preimplantation embryos. Mol Hum Reprod 1999, 5:234-239.

27. Kawamura K, Fukuda J, Kumagai J, Shimizu Y, Kodama H, Nakamura A, Tanaka T: Gonadotropin-releasing hormone I analog acts as an antiapoptotic factor in mouse blastocysts. Endocrinology 2005, 146:4105-4116.

28. Nam DH, Lee SH, Kim HS, Lee GS, Jeong YW, Kim S, Kim JH, Kang SK, Lee BC, Hwang WS: The role of gonadotropin-releasing hormone (GnRH) and its receptor in development of porcine preimplantation embryos derived from in vitro fertilization. Theriogenology 2005, 63:190-201.

29. Raga F, Casan EM, Kruessel J, Wen Y, Bonilla-Musoles F, Polan ML: The role of gonadotropin-releasing hormone in murine preimplantation embryonic development. Endocrinology 1999, 140:3705-3712.

30. Islami D, Chardonnens D, Campana A, Bischof P: Comparison of the effects of GnRH-I and GnRH-II on HCG synthesis and secretion by first trimester trophoblast. Mol Hum Reprod 2001, 7:3-9.

31. Lin LS, Roberts VJ, Yen SS: Expression of human gonadotropin-releasing hormone receptor gene in the placenta and its functional relationship to human chorionic gonadotropin secretion. J Clin Endocrinol Metab 1995, 80:580-585.

32. Klemmt PA, Liu F, Carver JG, Jones C, Brosi D, Adamson J, Mardon HJ, McVeigh E: Effects of gonadotrophin releasing hormone analogues on human endometrial stromal cells and embryo invasion in vitro. Hum Reprod 2009, 24:2187-2192.

33. Raga F, Casan EM, Kruessel JS, Wen Y, Huang HY, Nezhat C, Polan ML: Quantitative gonadotropin-releasing hormone gene expression and immunohistochemical localization in human endometrium throughout the menstrual cycle. Biol Reprod 1998, 59:661-669.

34. Shemesh M: Actions of gonadotrophins on the uterus. Reproduction 2001, 121:835-842.

35. Chou CS, Tai CJ, MacCalman CD, Leung PC: Dose-dependent effects of gonadotropin releasing hormone on matrix metalloproteinase (MMP)-2, and MMP-9 and tissue specific inhibitor of metalloproteinases-1 messenger ribonucleic acid levels in human decidual Stromal cells in vitro. J Clin Endocrinol Metab 2003, 88:680-688.

36. Raga F, Casan EM, Wen Y, Huang HY, Bonilla-Musoles F, Polan ML: Independent regulation of matrix metalloproteinase- 9 , tissue inhibitor of metalloproteinase-1 (TIMP-1), and TIMP-3 in human endometrial stromal cells by gonadotropin-releasing hormone: implications in early human implantation. J Clin Endocrinol Metab 1999, 84:636-642.

37. Meresman GF, Bilotas MA, Lombardi E, Tesone M, Sueldo C, Baranao Rl: Effect of GnRH analogues on apoptosis and release of interleukin-1beta and vascular endothelial growth factor in endometrial cell cultures from patients with endometriosis. Hum Reprod 2003, 18:1767-1771.

38. Wu HM, Wang HS, Huang HY, Soong YK, MacCalman CD, Leung PC: GnRH signaling in intrauterine tissues. Reproduction 2009, 137:769-777.

39. Zhang X, Bocca S, Franchi A, Anderson S, Kaur M, Bajic VB, Oehninger S: Do $\mathrm{GnRH}$ analogues directly affect human endometrial epithelial cell gene expression? Mol Hum Reprod 2010, 16:347-360.

40. Hugues JN, Cedrin-Durnerin I, Bstandig B, Theron-Gerard L, Grange D, Laffy A, Clement P, Hamidi J, Sifer C, Poncelet C: Administration of gonadotropin-releasing hormone agonist during the luteal phase of GnRH-antagonist IVF cycles. Hum Reprod 2006, 21:i3.

doi:10.1186/1477-7827-8-107

Cite this article as: Oliveira et al.: Administration of single-dose GnRH agonist in the luteal phase in ICSI cycles: a meta-analysis. Reproductive Biology and Endocrinology 2010 8:107.

\section{Submit your next manuscript to BioMed Central and take full advantage of:}

- Convenient online submission

- Thorough peer review

- No space constraints or color figure charges

- Immediate publication on acceptance

- Inclusion in PubMed, CAS, Scopus and Google Scholar

- Research which is freely available for redistribution

Submit your manuscript at www.biomedcentral.com/submit
C Biomed Central 